\title{
Erratum to: Traditional Food Items in Ogimi, Okinawa: L-Serine Content and the Potential for Neuroprotection
}

\author{
Paul Alan $\operatorname{Cox}^{1} \cdot$ James S. Metcalf ${ }^{1}$
}

Published online: 23 February 2017

(C) Springer Science+Business Media New York 2017

\section{Erratum to: Curr Nutr Rep}

DOI 10.1007/s13668-017-0191-0

There is an error under the Results section, which currently reads "This is about $6 \mathrm{~g}$ /day above the daily L-serine intake $(2.53 \mathrm{~g} /$ day $)$ from all sources consumed by women in the USA and twice the L-serine intake $(7.15 \mathrm{~g} /$ day $)$ consumed by the 99th percentile of US women age 71+." The sentence should read "This is about $6 \mathrm{~g} /$ day above the daily L-serine intake $(2.53 \mathrm{~g} /$ day $)$ from all sources consumed by women in the USA and nearly twice the L-serine intake ( $4.46 \mathrm{~g} /$ day) consumed by the 99th percentile of US women age 71+."

Also a typographical error was found in the Ethnobotanical Survey section. The phrase "...as was the manufacturer of flour..." should be read as "... as was the manufacture of flour....".

The online version of the original article can be found at http://dx.doi.org/ 10.1007/s13668-017-0191-0.

Paul Alan Cox

paul@ethnomedicine.org

James S. Metcalf

james@ethnomedicine.org

1 Brain Chemistry Labs, Institute for Ethnomedicine, Box 3464,

Jackson, WY 83001, USA 